\title{
Drugs affecting milk supply during lactation
}

\section{SUMMARY}

There are morbidity and mortality benefits for infants who are breastfed for longer periods. Occasionally, drugs are used to improve the milk supply.

Maternal perception of an insufficient milk supply is the commonest reason for ceasing breastfeeding. Maternal stress or pain can also reduce milk supply.

Galactagogues to improve milk supply are more likely to be effective if commenced within three weeks of delivery. The adverse effects of metoclopramide and domperidone must be weighed against the benefits of breastfeeding.

Dopamine agonists have been used to suppress lactation. They have significant adverse effects and bromocriptine should not be used because of an association with maternal deaths.

\section{Introduction}

Breast milk is a complex, living nutritional fluid that contains antibodies, enzymes, nutrients and hormones. Breastfeeding has many benefits for babies such as fewer infections, increased intelligence, probable protection against overweight and diabetes and, for mothers, cancer prevention. ' The World Health Organization recommends mothers breastfeed exclusively for six months postpartum.

Breastfeeding is influenced by many complex physiological and psychosocial factors. While most women have a desire to breastfeed, some do not. In high-income countries such as Australia the duration of breastfeeding is shorter than in lowand middle-income countries. A 2011 Australian Institute of Health and Welfare survey estimated that only $56 \%$ of infants younger than six months were exclusively breastfed, and by 12 months this dropped to $30 \%$. While breastfeeding should be encouraged, a woman's right to choose not to breastfeed should be respected. By understanding the reasons for their decision, strategies can be offered to support their choice.

\section{Physiology of lactation}

Milk production begins between 10 and 22 weeks gestation. Within 48 hours of delivery, the mother produces a small amount of milk, mainly colostrum. However, it is not until serum progesterone decreases sufficiently, up to four days postpartum, that milk supply becomes more plentiful. Lactogenesis may be delayed if the baby is premature.

Milk production is controlled by a complex interplay of hormones and neurotransmitters. Prolactin is secreted by the anterior pituitary in response to nipple stimulation. Its release is inhibited by dopamine from the hypothalamus. Within a month of delivery, basal prolactin returns to pre-pregnant levels in nonbreastfeeding mothers. It remains elevated in nursing mothers, with peaks in response to infant suckling. Drugs that act on dopamine can affect lactation.

In response to suckling, oxytocin is released from the posterior pituitary to enable the breast to let down milk. Oxytocin release is inhibited by catecholamines produced if the mother is stressed or experiencing pain.

The feedback inhibitor of lactation is a peptide found in breast milk. If the milk is not removed, the inhibitor will stop milk production. When the baby cannot suckle, expressing the milk will remove the inhibitor and encourage more production.

\section{Milk supply}

A maternal perception of insufficient milk is the commonest reason for ceasing breastfeeding. Some women have difficulty producing sufficient breast milk after a difficult labour, delayed initiation of breastfeeding, separation due to the baby being preterm, formula substitution, cracked nipples or maternal illness.

Support and reassurance are as important as determining the cause of the problem, before recommending infant formula. Simple strategies can restore confidence and assist in increasing milk supply. Encourage the mother to 'hang in a bit longer' as babies have adequate nutrient stores to cover the first postpartum week. Make sure she is well hydrated, has adequate nutrient intake and home support, and reassure her that a crying baby is not necessarily a hungry baby. Increase the frequency of feeding or
Treasure M McGuire

Assistant director

Practice and Development Mater Pharmacy Services

Mater Health Services Brisbane

Conjoint senior lecturer School of Pharmacy University of Queensland

Associate professor Pharmacology Faculty of Health Sciences and Medicine Bond University Gold Coast

\section{Keywords}

breastfeeding, cabergoline, domperidone, galactagogues, lactation, metoclopramide, prolactin

Aust Prescr 2018;41:7-9 https://doi.org/10.18773/ austprescr.2018.002

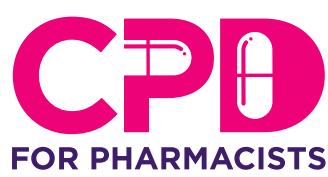

This article has a continuing professional development activity for pharmacists available at https://learn.nps.org.au 
offer the baby both breasts at each feed. Check the baby's suckling patterns, ensure adequate but not excessive hydration and avoid the use of a dummy.

Where feeding problems persist, referral to a lactation consultant is an appropriate option.

Maintaining the milk supply may also be problematic as the baby grows. An infant typically requires about $150 \mathrm{~mL} / \mathrm{kg} /$ day. So, to feed a $9 \mathrm{~kg}$ versus $3 \mathrm{~kg}$ baby daily ( $1350 \mathrm{~mL}$ vs $450 \mathrm{~mL}$ ) can be a physiological challenge for some women.

\section{Galactagogues}

Antipsychotic drugs can increase pituitary prolactin secretion and breast milk production through dopamine antagonism, but the gastrointestinal motility drugs metoclopramide and domperidone are most commonly used off label as galactagogues. Metoclopramide and domperidone block dopamine $D_{2}$ receptors in the anterior pituitary and, in a limited number of clinical trials, they have had modest efficacy over placebo in initiating and maintaining lactation. ${ }^{2}$ The best chance for efficacy is if the galactagogue is started within three weeks of delivery. ${ }^{3}$

The safe duration of galactagogue therapy is controversial. Although increased prolactin can be detected within eight hours of the first dose, about two weeks is required for the breast changes required to sustain milk production. Current recommendations of 10-14 days are based on a limited number of controlled studies and the limited number of longer term controlled clinical trials.

\section{Metoclopramide}

Metoclopramide is a centrally acting drug. It can increase milk supply by $66-100 \%$ within $2-5$ days in total daily doses of 30-45 mg. While the relative dose in milk ranges from 4.7-14.3\%, adverse outcomes in infants have not been reported. ${ }^{4}$ However:

- effects are dose dependent, with a threshold of $10 \mathrm{mg}$

- doses need to be administered regularly three times a day

- only 50-85\% of women with low milk supply will respond

- maternal adverse effects include diarrhoea and depression

- there is a theoretical risk of extrapyramidal adverse effects in the baby

- if metoclopramide is discontinued rapidly, there can be a significant rebound decline in milk supply.

\section{Domperidone}

Domperidone is a peripheral dopamine antagonist. At doses of 10-20 mg three times daily it has comparable efficacy to metoclopramide. ${ }^{4}$ Little domperidone passes into milk (relative infant dose $0.01-0.04 \%$ ), so the risk of extrapyramidal effects in the baby is less than with metoclopramide. ${ }^{4}$

In 2004, the US Food and Drug Administration (FDA) issued an alert that domperidone could cause cardiac arrhythmias. This was in response to its illegal importation into the USA by breastfeeding mothers. The data related to historical cases of high-dose, intravenous use in sick patients receiving cancer chemotherapy. Two case control studies using oral domperidone in a general population supported this rare association. However, only three probable case reports in lactating women have been received by the FDA in postmarketing surveillance. ${ }^{5}$ Concomitant use of moderate or strong inhibitors of cytochrome P450 3A4 such as ketoconazole can increase plasma concentrations of domperidone and therefore the risk of QT prolongation.

In 2013, the Pharmacovigilance Risk Assessment Committee of the European Medicines Agency recommended that the daily oral dose be restricted to a maximum of $30 \mathrm{mg}$ and that domperidone not be used for longer than one week. It is therefore important that women being offered domperidone as a galactagogue have tried non-pharmacological strategies first. They need to be aware of the very low risk of QT prolongation and weigh this against the benefits of breastfeeding.

\section{Complementary medicines}

Herb-derived galactagogues have been used for centuries in folk medicine to augment lactation. These plants contain lipophilic, pharmacologically active constituents which, if taken in sufficient quantity, can pass into the breast milk. While there are generally few adverse effects (Table), there is limited evidence of efficacy. Most of the supporting evidence is based on case reports, or historical use.

\section{Lactation suppression}

Some women may require lactation suppression after miscarriage, stillbirth, maternal illness or when they do not wish to breastfeed. While breast stimulation should be avoided, there is a risk of engorgement if the breasts are not drained.

Pharmacological options all have significant adverse effects. The dopamine agonist bromocriptine was associated with maternal deaths from myocardial infarction and is no longer 
recommended. It has been replaced by a single $1 \mathrm{mg}$ dose of long-acting cabergoline, ideally taken on the first postpartum day. The common adverse effects are nausea, headache and dizziness. If the woman changes her mind, it can be difficult to restore milk production.

Other drugs no longer used include large doses of pyridoxine and diuretics. Oestrogen is avoided because of the risk of thromboembolism.

\section{Conclusion}

Breast feeding is a natural process with benefits for both mother and baby. Some women find it difficult to breastfeed, but many problems can be overcome with reassurance and support.

Occasionally, non-drug approaches may not increase the supply of milk. There is limited evidence for the off-label use of domperidone and metoclopramide. However, if a drug is considered for increasing milk supply, discuss with the mother a trial of an agreed dose, for a maximum agreed duration beginning as soon as feasible postpartum. Also discuss the potential for adverse effects.

There are few indications for using drugs to suppress lactation. Cabergoline has been used, but bromocriptine should be avoided because of maternal deaths. $<$

Conflict of interest: none declared

\section{REFERENCES}

1. Victora CG, Bahl R, Barros AJ, França GV, Horton S, Krasevec J, et al.; Lancet Breastfeeding Series Group. Breastfeeding in the 21st century: epidemiology, mechanisms, and lifelong effect. Lancet 2016;387:475-90. https://doi.org/10.1016/S0140-6736(15)01024-7

2. Donovan TJ, Buchanan K. Medications for increasing milk supply in mothers expressing breastmilk for their preterm hospitalised infants. Cochrane Database Syst Rev 2012:CD005544. https://doi.org/10.1002/14651858.CD005544.pub2

\section{Table Adverse effects of herbs used as galactagogues}

\begin{tabular}{|c|c|}
\hline Herb & Adverse effects \\
\hline $\begin{array}{l}\text { Alfalfa } \\
\text { Medicago sativa }\end{array}$ & Dose-related bleeding \\
\hline $\begin{array}{l}\text { Blessed thistle } \\
\text { Cnicus benedictus }\end{array}$ & $\begin{array}{l}\text { Gastric irritation and potential allergies, as it is part of } \\
\text { the ragweed family }\end{array}$ \\
\hline $\begin{array}{l}\text { Chaste tree } \\
\text { Vitex agnus-castus }\end{array}$ & $\begin{array}{l}\text { Nausea, vomiting, irritation, pruritus, rash, headache, } \\
\text { increased menstruation }\end{array}$ \\
\hline $\begin{array}{l}\text { Dill } \\
\text { Anethum graveolens }\end{array}$ & Alterations in sodium balance \\
\hline $\begin{array}{l}\text { Fennel } \\
\text { Foeniculum vulgare }\end{array}$ & Allergic reactions, dermatitis (photo and contact) \\
\hline $\begin{array}{l}\text { Fenugreek seed } \\
\text { Trigonella foenum-graecum }\end{array}$ & $\begin{array}{l}\text { Hypoglycaemia, hypertension, diarrhoea and maple } \\
\text { syrup body odour in mother } \\
\text { Allergy potential as part of the peanut family }\end{array}$ \\
\hline $\begin{array}{l}\text { Goat's rue } \\
\text { Galega officinalis }\end{array}$ & $\begin{array}{l}\text { Hypoglycaemia, hypotension, coughing, dose-related } \\
\text { toxicity }\end{array}$ \\
\hline $\begin{array}{l}\text { Milk thistle (silymarin) } \\
\text { Silybum marianum }\end{array}$ & Allergic reactions, diarrhoea \\
\hline $\begin{array}{l}\text { Malunggay } \\
\text { Moringa oleifera }\end{array}$ & Hypoglycaemia, sedation \\
\hline $\begin{array}{l}\text { Raspberry leaf } \\
\text { Rubus idaeus }\end{array}$ & Hypersensitivity reactions, changes in blood glucose \\
\hline $\begin{array}{l}\text { Shatavari } \\
\text { Asparagus racemosus }\end{array}$ & Possible teratogenicity - avoid in pregnancy \\
\hline $\begin{array}{l}\text { Damiana } \\
\text { Turnera diffusa }\end{array}$ & $\begin{array}{l}\text { Hepatotoxicity, confusion and hallucinations with high- } \\
\text { dose Turnera }\end{array}$ \\
\hline
\end{tabular}

3. Ehrenkranz RA, Ackerman BA. Metoclopramide effect on faltering milk production by mothers of premature infants. Pediatrics 1986;78:614-20.

4. Hale TW, Rowe HE. Medications and mothers' milk: a manual of lactational pharmacology. 17th ed. New York: Springer Publishing Company; 2017.

5. Sewell CA, Chang CY, Chehab MM, Nguyen CP. Domperidone for lactation: what health care providers need to know. Obstet Gynecol 2017;129:1054-8. https://doi.org/10.1097/ AOG.0000000000002033

\section{FURTHER READING}

Australian Institute of Health and Welfare. 2010 Australian national infant feeding survey: indicator results. Canberra: AlHW; 2011. https://www.aihw.gov.au/reports/mothers-babies/ 2010-australian-national-infant-feeding-survey/contents/tableof-contents [cited 2018 Jan 1]

Bazzano AN, Hofer R, Thibeau S, Gillispie V, Jacobs M, Theall KP. A review of herbal and pharmaceutical galactagogues for breastfeeding. Ochsner J 2016;16:511-24.

European Medicines Agency. PRAC recommends restricting use of domperidone [press release]. 2014 Mar 7.

http://www.ema.europa.eu/docs/en_GB/document_library/ Press_release/2014/03/WC500162558.pdf [cited 2018 Jan 1] Grzeskowiak LE, Amir LH. Pharmacological management of low milk supply with domperidone: separating fact from fiction. Med J Aust 2014;201:257-8. https://doi.org/10.5694/mja14.00626
McGuire TM. Safe use of drugs while breastfeeding. In: Brodribb W, editor. Breastfeeding management in Australia. 4th ed. Melbourne: Australian Breastfeeding Association; 2012. p. 266-301.

Mortel M, Mehta SD. Systematic review of the efficacy of herbal galactogogues. J Hum Lact 2013;29:154-62. https://doi.org/10.1177/0890334413477243

US Food and Drug Administration. FDA warns against women using unapproved drug, domperidone, to increase milk production. Silver Spring (MD); 2007. https://www.fda.gov/ Drugs/DrugSafety/InformationbyDrugClass/ucm173886.htm [cited 2018 Jan 1]

WHO/UNICEF. Global nutrition targets 2025: breastfeeding policy brief (WHO/NMH/NHD/14.7). Geneva: World Health Organization; 2014. http://www.who.int/nutrition/publications/ globaltargets2025_policybrief_breastfeeding/en [cited 2018 Jan 1] 